\title{
Cytogenetic studies on meiotic chromosome behaviors in sterile Oriental $x$ Trumpet lily
}

\author{
J.R. Luo ${ }^{1,2}$, J.M. Van Tuyl², P. Arens² and L.X. Niu' ${ }^{1}$ \\ ${ }^{1}$ College of Forestry, Northwest Agricultural and Forestry University, \\ Yangling, Shaanxi, China \\ 2Plant Breeding, Wageningen University and Research Centre, Wageningen, \\ The Netherlands \\ Corresponding author: L.X. Niu \\ E-mail: niulixin@nwsuaf.edu.cn
}

Genet. Mol. Res. 12 (4): 6673-6684 (2013)

Received February 2, 2013

Accepted October 4, 2013

Published December 13, 2013

DOI http://dx.doi.org/10.4238/2013.December.13.1

\begin{abstract}
In order to determine the reasons for pollen sterility in lily hybrids, four diploid sterile Oriental x Trumpet (OT) lily cultivars ('Nymph', 'Gluhwein', 'Yelloween', and 'Shocking') were used to investigate the meiotic chromosome behaviors in pollen mother cells (PMCs), using genomic in situ hybridization and conventional cytological methods. At metaphase I, chromosome associations were quite variable, not only among different genotypes but also in different PMCs of the same genotype. In addition to bivalents, a certain amount of univalent, trivalents, and quadrivalents were observed in all of the investigated genotypes. In addition, ring octavalents and ring hexavalents were observed in 'Nymph'. Even dodecavalents were observed in 'Nymph'. These abnormal chromosome associations at metaphase I implied the occurrence of chromosome interchanges (translocation) in these intersectional hybrids. At anaphase-telophase, a large number of laggard chromosomes and different kinds of chromosome bridge configurations were observed. At the tetrad stage, micronuclei and polyads were also found in many PMCs. All of these
\end{abstract}


abnormal chromosome behaviors in PMCs were responsible for the pollen sterility in lily hybrids.

Key words: Pollen sterility; Meiosis; Chromosome behaviors; Lilium

\section{INTRODUCTION}

The genus Lilium comprises about 100 species, and all of them are dispersed in the Northern Hemisphere (McRae, 1998). The diversity of flower color, shape, fragrance, and other phenotypic and physiological characteristics are found in the wild species. Based on 15 morphological characteristics, they are classified into seven taxonomic sections: Lilium, Martagon, Pseudolirium, Archelirion, Sinomartagon, Leucolirion, and Oxypetalum (Comber, 1949; De Jong, 1974). Each section has its own unique set of horticultural traits. It is desirable to combine or introgress valuable horticultural traits from different lily genomes (sections) into cultivars through intersectional hybridization. However, hybridization between the cultivars or species from different taxonomic sections in the genus Lilium is generally difficult because of pre- and post-fertilization barriers (Van Tuyl et al., 2002). In the past few years, owing to the development of pollination and embryo rescue techniques (Asano and Myodo, 1977a,b; Asano, 1978, 1980; Van Tuyl et al., 1991), a range of intersectional hybrids such as LA (Longiflorum x Asiatic), OT (Oriental x Trumpet), LO (Longiflorum x Oriental), and OA (Oriental x Asiatic) involving distantly related cultivars/species have been cultivated. These intersectional hybrids possess many unique horticultural characteristics that their parents do not have. However, the pollen of these intersectional hybrids is usually sterile and cannot be used for further crossbreeding. Therefore, it is valuable to investigate the meiotic development in pollen mother cells (PMCs) to determine the reasons for the pollen sterility in lily hybrids.

Genomic in situ hybridization (GISH) is a powerful and effective molecular cytogenetic tool, which has been successfully used in Lilium to discriminate parental genomes of the $\mathrm{F}_{1}$ interspecific hybrids and to detect intergenomic recombinant chromosomes in the $\mathrm{BC}_{1}$ and $\mathrm{BC}_{2}$ progenies (Karlov et al., 1999; Lim, 2000; Barba-Gonzalez, 2005). Therefore, it can be an ideal technique to investigate homologous chromosome pairing and other meiotic chromosome behaviors in distant Lilium hybrids.

In the present study, four sterile OT lily cultivars were investigated for their meiotic chromosome behaviors during microsporogenesis with conventional cytological methods and the GISH technique. A number of aberrant meiotic chromosome behaviors were detected and analyzed.

\section{MATERIAL AND METHODS}

\section{Plant material}

Four diploid sterile $\mathrm{F}_{1}$ OT lily cultivars ('Nymph', 'Gluhwein', 'Yelloween', and 'Shocking') were used to investigate the homologous chromosome behavior during microsporogenesis.

All the cultivars were supplied by a Dutch lily breeding company. They were grown in a greenhouse following standard growing conditions applicable for lily cultivation. 


\section{Chromosome preparation with anthers}

Young anthers at the prophase I to telophase II stages were collected from different sized flower buds and fixed in Carnoy's solution (1:3 acetic acid-ethanol) for $24 \mathrm{~h}$ at room temperature. After fixing, the anthers were cut in the middle, and PMCs were spread on the slide; then, $16 \mu \mathrm{L} 2 \%$ aceto-carmine was swiftly added and gently mixed with the PMCs. The slide was covered with a square plastic cover, pressed gently with the thumb, and finally examined under a light microscope (Carl Zeiss, West Germany). Anthers at the proper meiotic stage were incubated in $10 \mathrm{mM}$ citrate buffer, $\mathrm{pH} 4.5$, containing $1 \%$ cellulase RS (w/v), $1 \%$ pectolyase Y23 (w/v), and $1 \%$ cytohelicase (w/v), for 60 to $70 \mathrm{~min}$ at $37^{\circ} \mathrm{C}$. A drop of $60 \%$ acetic acid was immediately added to the meristem and mixed gently with a needle, and then smeared for several seconds on a slide heater. The slides were then washed with 3:1 ethanolacetic acid (v/v) and air-dried. The best slides that had good chromosome spreads were selected under a light microscope for GISH analysis.

\section{GISH}

Total genomic DNA was extracted from leaves. Before labeling, the total genomic DNA was sonicated to 0.5 to $5 \mathrm{~kb}$ and used as a probe. Oriental DNA was labeled with digoxigenin-11-dUTP and Trumpet DNA was labeled with biotin-16-dUTP by nick translation according to the manufacturer protocols (Roche Diagnostics GmbH, Mannheim, Germany).

In situ hybridization was carried out according to Lim (2000). In short, the hybridization mixture contained $2 \times$ SSC, $50 \%$ formamide, $10 \%$ sodium dextran sulfate $(\mathrm{w} / \mathrm{v}), 0.25 \%$ sodium dodecyl sulfate $(\mathrm{w} / \mathrm{v})$, and $3.0 \mathrm{ng} / \mu \mathrm{L}$ labeled probe DNA. The hybridization mixture was denatured in water bath at $72^{\circ} \mathrm{C}$ for $10 \mathrm{~min}$ and cooled on ice for $10 \mathrm{~min}$. For each slide, $40 \mu \mathrm{L}$ hybridization mixture was added, followed by denaturing at $80^{\circ} \mathrm{C}$ for $5 \mathrm{~min}$ and incubating overnight at $37^{\circ} \mathrm{C}$ in a humid chamber. After hybridization, the slides were washed twice in $0.1 \mathrm{x}$ SSC [including $10 \%$ formamide $(\mathrm{v} / \mathrm{v})]$ at $42^{\circ} \mathrm{C}$ for $5 \mathrm{~min}$ each time. Biotin was detected using the Cy-3-conjugated streptavidin-antistreptavidin system (Vector Laboratories, UK). Digoxigenin was detected by using the FITC-antidigoxigenin system (Boehringer, Mannheim, Germany). The chromosomes were counterstained with 4,6-diamidino-2-phenylindole (DAPI; Sigma, US) in Vectashield (Vector Laboratories, UK). Preparations were analyzed using an epifluorescence microscope (Carl Zeiss) and photographed with a digital camera (Canon, Japan) attached to the microscope.

\section{RESULTS}

\section{Chromosome associations at diakinesis-metaphase I}

Using the GISH technique and traditional cytogenetic method, the frequencies and configuration of the chromosome associations in the four sterile intersectional hybrids were observed, as shown in Table 1. Some pictures of the chromosome associations are showed in Figure 1. The chromosome associations were quite variable, not only among different genotypes but also in different PMCs within the same genotype. The mean frequency of bivalents per cell was highest (8.9) in 'Nymph.' The lowest frequency of bivalents per cell (3.0) was observed in 'Shocking'. Usually, bivalents were formed involving the homologous chromosomes (Figure 1A, B, and $\mathrm{C})$. There were also instances of bivalents resulting from non-homologous association of two 
chromosomes in the same genome (Figure 1D). In addition to univalents and bivalents, a certain amount of trivalents and quadrivalents were observed in all of the investigated genotypes (Figure $1 \mathrm{E}$ and $\mathrm{F}$ ). Besides these, ring octavalents and ring hexavalents were observed in 'Nymph' (Figure 1G and Figure 2A). Even dodecavalents were observed in 'Nymph' (Figure 1H). All of these abnormal chromosome associations at diakinesis-metaphase I implied the occurrence of chromosome interchanges (translocation) in these intersectional hybrids. Specifically, the occurrence of ring octavalents and hexavalents indicated that cyclical translocation must take place in this genotype. This is the first report on cyclical translocation in Lilium.

Table 1. Chromosome association at diakinesis-metaphase I in $\mathrm{F}_{1}$ Oriental x Trumpet lily.
\begin{tabular}{lcccccc}
\hline Genotype & No. of cells analyzed & \multicolumn{7}{c}{ Chromosome association } \\
\cline { 3 - 7 } & & Univalent & Bivalent & No. of bivalents per cell & Trivalent & Quadrivalent \\
\hline 'Gluhwein' & 140 & 1548 & 852 & $6.4(3-9)$ & $20(14.3 \%)$ & $12(8.6 \%)$ \\
'Shocking' & 135 & 2418 & 361 & $3.0(2-5)$ & $12(8.9 \%)$ & $16(11.9 \%)$ \\
'Nymph* & 181 & 1152 & 1556 & $8.9(7-12)$ & $4(2.2 \%)$ & $16(8.8 \%)$ \\
'Yelloween' & 128 & 2016 & 502 & $4.1(2-6)$ & $6(4.7 \%)$ & $8(6.3 \%)$ \\
\hline
\end{tabular}

*Dodeca-valent and ring octavalent were also observed in this genotype.
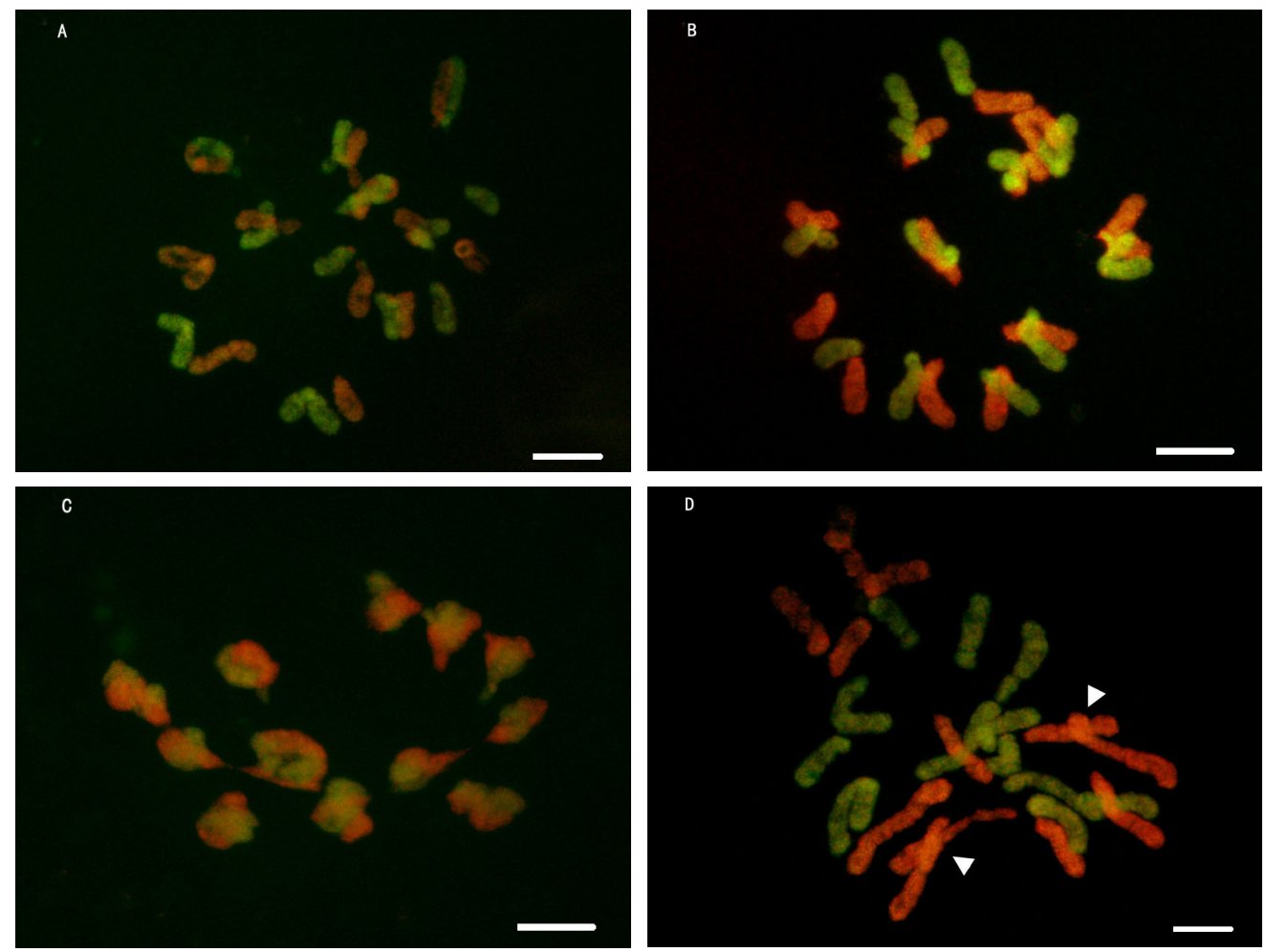

Figure 1. Chromosome association in sterile Oriental x Trumpet lily. A. Chromosome pairing in 'Gluhwein' (7 II+10I); B., C. chromosome pairing in 'Nymph' (9 II+6I, 12 II); D. non-homologous chromosome pairing in 'Gluhwein' (arrow); E. trivalent in 'Gluhwein' (arrow); F. quadrivalent in 'Shocking' (arrow); G. ring octavalent 'Nymph'; H. dodeca-valent in 'Nymph'. In all cases, green chromosomes represent Oriental lily chromosomes and red chromosomes represent Trumpet lily chromosomes. Bar $=10 \mu \mathrm{m}$.

Continued on next page 
Figure 1. Continued.
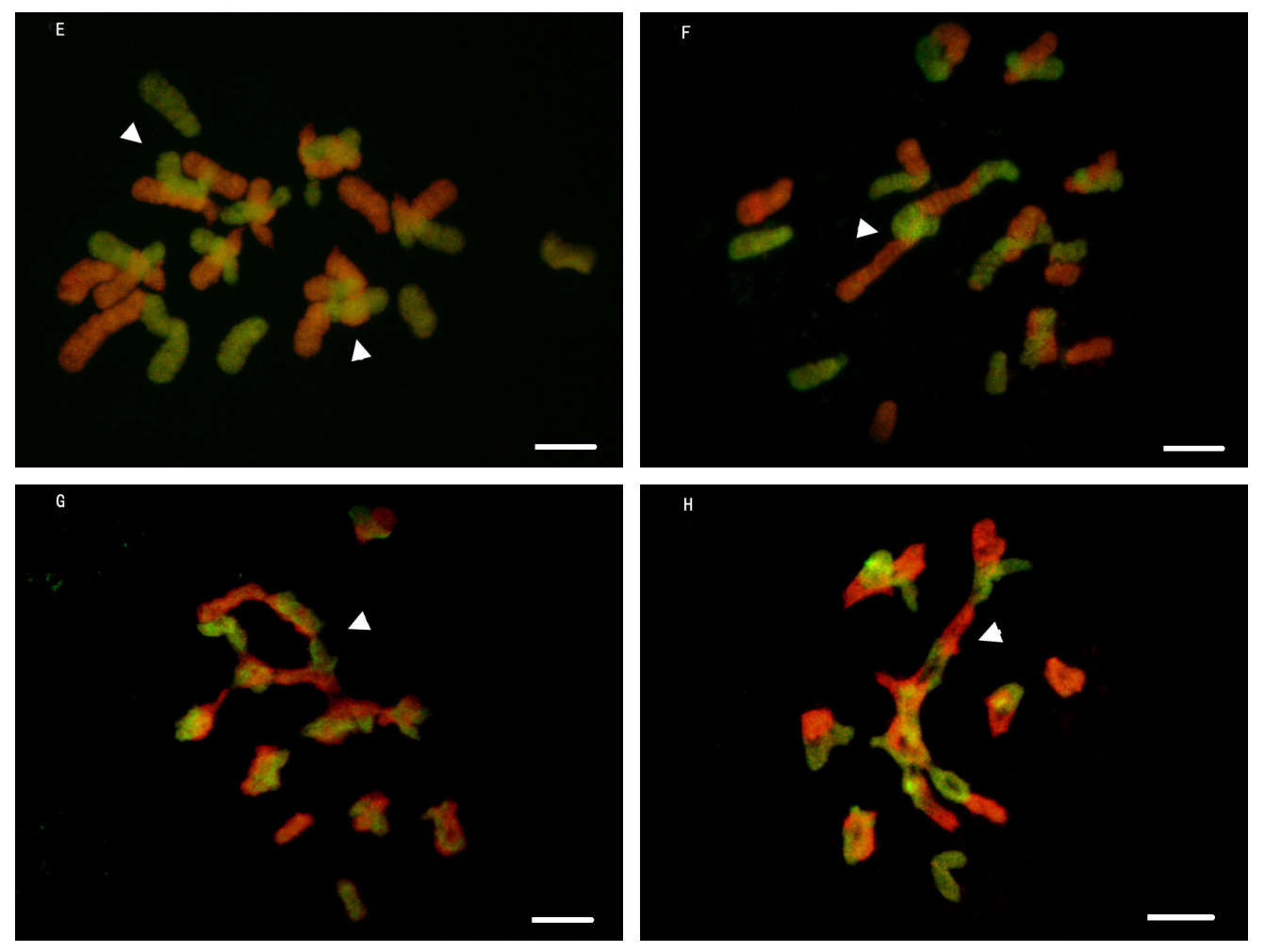

\section{Chromosome behaviors at anaphase I-telophase I}

More than 260 cells at anaphase I-telophase I were checked using the conventional staining method for each cultivar. A large number of abnormal chromosome segregations were observed (Table 2). Among these abnormal chromosome behaviors, laggard chromosome (Figure 2B) was the most common, which occurred in all the investigated genotypes. The percentage of lagging chromosome varied from 54 ('Nymph') to 90\% ('Shocking'). Besides the lagging chromosomes, anaphase bridges were also common in these four interspecific hybrids. In the cases of 'Gluhwein' and 'Nymph', 29 and 24\% PMCs had chromosome bridges, respectively. Compared with 'Gluhwein' and 'Nymph', the percentage of chromosome bridges in 'Shocking' and 'Yelloween' was relative lower (13 and 2\%). Two different configurations of bridges were observed: one bridge and two bridges (Figure $2 \mathrm{C}$ and $\mathrm{D}$ ). In this investigation, one bridge was the most frequent, and observed in all genotypes ranging from 2 ('Yelloween') to $26 \%$ ('Gluhwein'). The configuration of two bridges was only observed in 'Gluhwein' and 'Nymph' with very low frequency (3 and 1\%). Besides the one-bridge and two-bridge configurations, another special chromosome bridge, 'thick bridge', was also detected in some PMCs in 'Shocking', which is usually caused by chromosome stickiness involving many chromosomes or entire genomes (Figure 2E and F). 

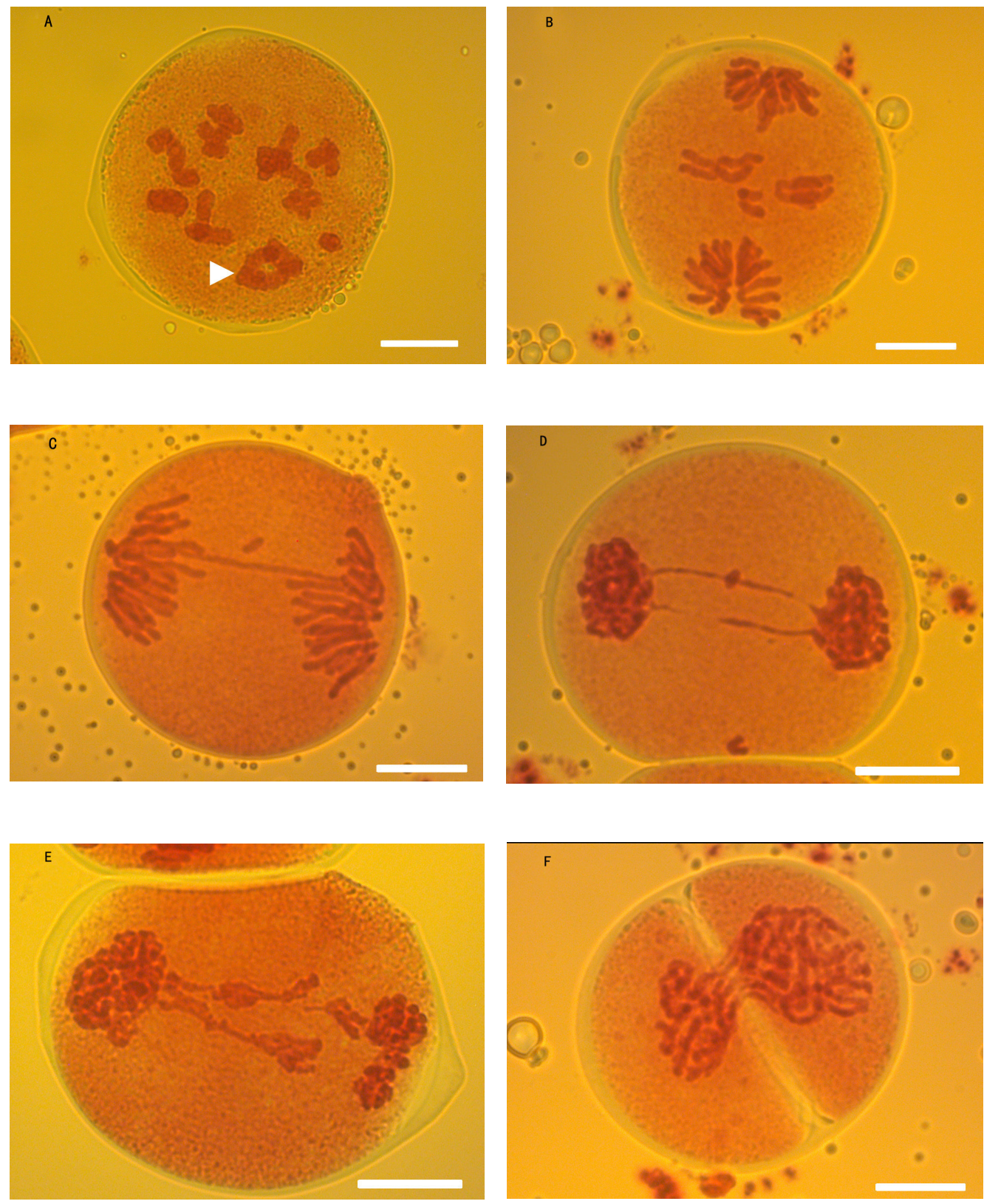

Figure 2. Abnormal meiotic chromosome behaviors in lily hybrids. A. Ring hexavalent; B. lagging chromosomes at anaphase I; C. one bridge-fragment; D. two bridges; E. F. thick chromosome bridge; G. lagging chromosome at anaphase II; H. I. J. anaphase II bridge; K. irregular orientation segregation; L. tetrad wih micronuclei; M. N. O. polyads with different numbers, size, and micronuclei; P. pollen grains of different sizes. Q. R. Scattered univalent in the cytoplasm. Bars $=20 \mu \mathrm{m}$. 
Figure 2. Continued.
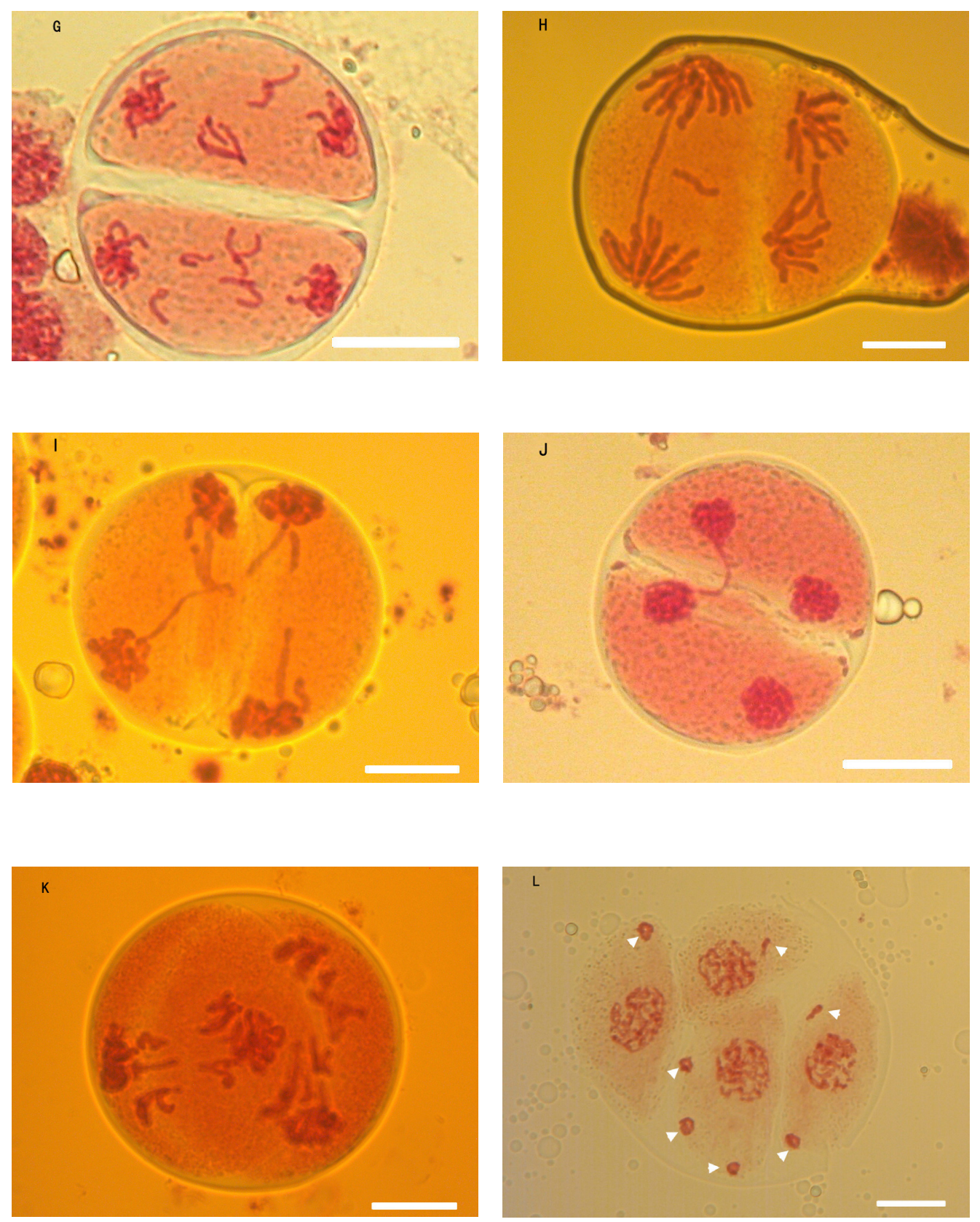

Continued on next page

Genetics and Molecular Research 12 (4): 6673-6684 (2013)

CFUNPEC-RP www.funpecrp.com.br 
Figure 2. Continued.
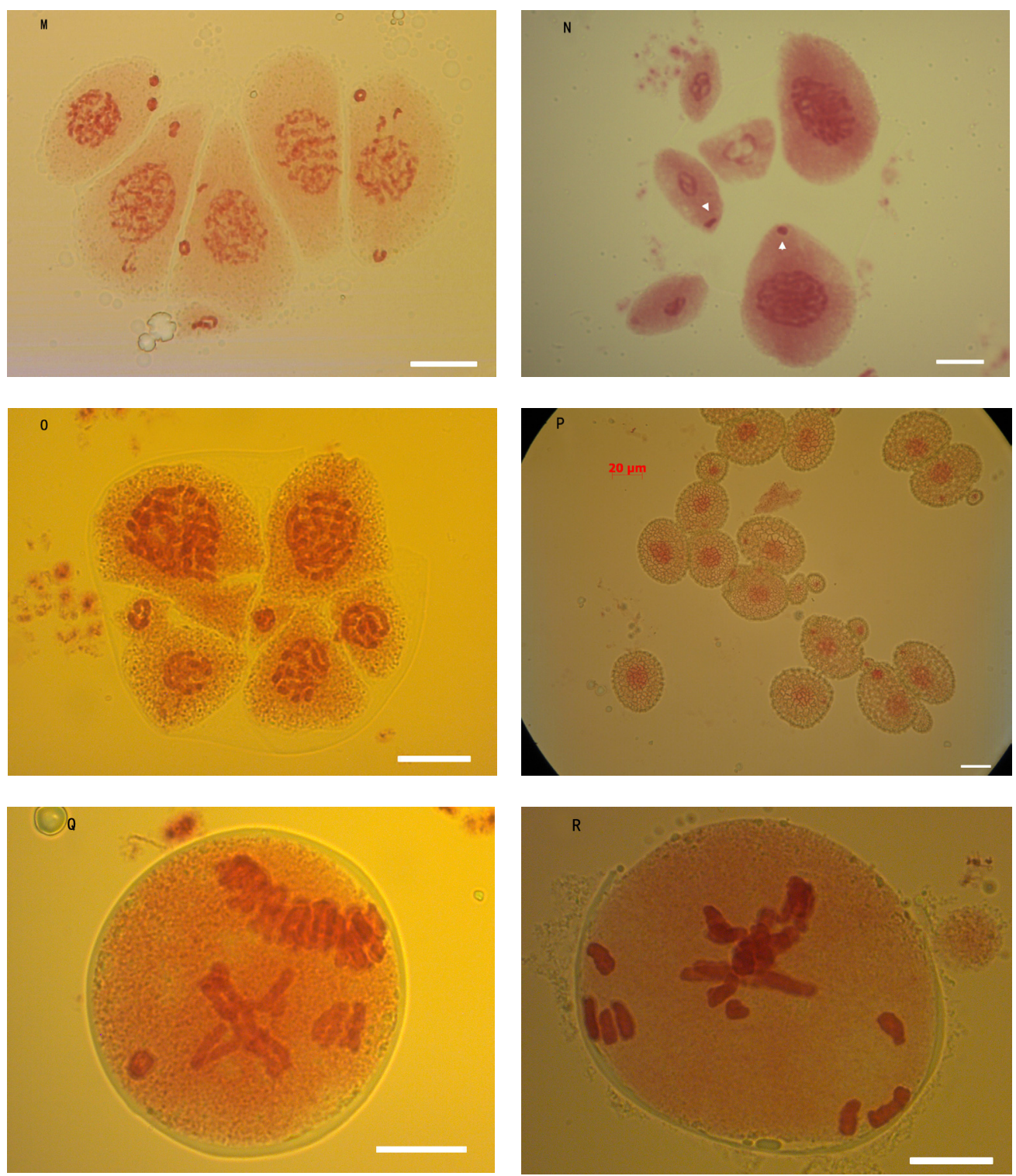

Table 2. Chromosome behaviors at anaphase I-telophase I in $\mathrm{F}_{1}$ Oriental $\mathrm{x}$ Trumpet lily.

\begin{tabular}{lcccc}
\hline Genotype & No. of cells analyzed & PMCs with laggards & \multicolumn{2}{c}{ No. of PMCs with bridge } \\
\cline { 3 - 5 } & & & One bridge & Two bridges \\
\hline 'Gluhwein' & 285 & $171(60 \%)$ & $3(26 \%)$ & $9(3 \%)$ \\
'Shocking' & 267 & $240(90 \%)$ & $63(13 \%)$ & 0 \\
'Nymph' & 274 & $147(54 \%)$ & $63(23 \%)$ & $5(1 \%)$ \\
'Yelloween' & 265 & $228(86 \%)$ & $5(2 \%)$ & 0 \\
\hline
\end{tabular}

Genetics and Molecular Research 12 (4): 6673-6684 (2013) 


\section{Chromosome behaviors at anaphase II-telophase II}

At anaphase II, lagging chromosomes were also very common in these four genotypes (Table 3, Figure 2G). The percentage of laggards varied from 43 to $89 \%$. Compared with anaphase I, chromosome bridge-fragments were relatively rare, but observed in some PMCs of 'Nymph', 'Shocking' and 'Gluhwein', and only the configuration of the one bridge-fragment was observed (Figure $2 \mathrm{H}$, I, and J). In some PMCs, irregular chromosome segregation (Figure 2K) was also found.

Table 3. Chromosome behaviors at anaphase II-telophase II in $\mathrm{F}_{1}$ Oriental x Trumpet lily.
\begin{tabular}{lccc}
\hline Genotype & No. of cells analyzed & PMCs with laggards & PMCs with bridge and fragment \\
\hline 'Gluhwein' & 218 & $128(59 \%)$ & $22(10 \%)$ \\
'Shocking' & 214 & $190(89 \%)$ & $6(3 \%)$ \\
'Nymph' & 210 & $90(43 \%)$ & $12(6 \%)$ \\
'Yelloween' & 207 & $180(87 \%)$ & 0 \\
\hline
\end{tabular}

\section{Chromosome behaviors at tetrad}

At the tetrad stage, a remarkable feature in these four genotypes was the occurrence of a micronucleus in many PMCs (Table 4, Figure 2L, M, and N). The frequency of PMCs with a micronucleus varied from 31 ('Nymph') to $86 \%$ ('Yelloween'). In addition, polyads with different numbers and sizes of spores and pollen grains of different sizes were also observed in some cells (Figure $2 \mathrm{O}$ and $\mathrm{P}$ ).

Table 4. Chromosome behaviors at tetrad in $\mathrm{F}_{1}$ Oriental $\mathrm{x}$ Trumpet lily.

\begin{tabular}{lccc}
\hline Genotype & No. of cells analyzed & Tetrad with micronuclei & Polyad \\
\hline 'Gluhwein' & 310 & $163(53 \%)$ & $12(4 \%)$ \\
'Shocking' & 280 & $235(84 \%)$ & $28(10 \%)$ \\
'Nymph' & 300 & $93(31 \%)$ & 0 \\
'Yelloween' & 290 & $249(86 \%)$ & $23(8 \%)$ \\
\hline
\end{tabular}

\section{DISCUSSION}

Chromosome pairing in hybrids is used to assess genomic relationships between species and provides an important starting point in alien chromosome introgression. Furthermore, the degree of differentiation between hybridizing taxa can be estimated by analyses of chromosome pairing behaviors and other meiotic abnormalities (Rieseberg et al., 2000). In the present study, many chromosome pairing configurations (univalent, bivalents, and multivalents) were observed in sterile diploid OT lily cultivars. In the case of 'Nymph,' the mean frequency of bivalents per cell was 8.9 , which was the highest in these four genotypes. The number of bivalents varied from 2 to 5 per cell in PMCs of 'Shocking', and the mean percentage of bivalents per cell was $3.0 \%$, which was the lowest in the investigated genotypes. Taking the abnormal chromosome behaviors in other meiotic stages into consideration, it indicated that the relationship of parents of 'Shocking' may be more remote than those of 'Nymph'. In addition, 12 bivalents per 
cell were also observed in very few PMCs of 'Nymph' (Figure 1C), which usually occurs in fertile genotypes. It implied that some pollen grains of 'Nymph' may be fertile.

Pachytene loops are proof of the presence of inversions, but pachytene chromosomes are technically difficult or impossible to analyze in most organisms, whereas observation of bridge-fragment configurations has been extensively applied as indirect evidence for the presence of paracentric inversions. On the basis of this evidence, a large number of plants were reported to have inversions, such as Aesculus (Upcott, 1936), Tulipa (Upcott, 1937), Fritillaria (Frankel, 1937), Zea mays (Morgan, 1950; Ting 1965), barley (Kreft, 1968), Agave (Brandham, 1969), soybeans (Ahmad et al., 1977), and Gasteria (Brandham, 1977). However, cytological evidence from paired chromosomes suggests that inversion is not responsible for all bridge-fragment configurations. This category includes sister chromatid bridges and variation of fragment size (Newman, 1966). These configurations can be explained by U-type exchanges (Jones and Brumpton, 1971; Couzin and Fox, 1973). This is an indication that the inversion in plants may be overestimated by some researchers in the previous studies. In the present investigation, a sister chromatid bridge (anaphase II bridge) was observed (Figure $2 \mathrm{H}, \mathrm{I}$, and J). At the same time, most fragment sizes in the bridge-fragment configuration at anaphase I remained stable in this study. All of these indicated that not only inversion but also U-type exchange took place in these interspecific lily hybrids. Inversions and U-type exchanges are both chromosomal structural aberrations that will result in gamete sterility.

The spindle apparatus is normally bipolar, and its bipolar symmetry plays a crucial role in the alignment of metaphase chromosomes and their poleward movement during anaphase. Meiotic plant spindle are initiated from the chromosomes by self-assembly (Baskin and Cande, 1990) and then assembled around the mass of chromosomes, and initially appear as poorly organized, often multipolar structures (Yu et al., 1999). Multiple spindle poles are visible at early prometaphase I. During mid-prometaphase I, the multiple spindle poles become concentrated into two poles, and the typical bipolar meiotic spindle is complete at metaphase I (Suzuki and Tanaka, 1999; Kitamura et al., 2009). Multiple spindles are a meiotic abnormality in which more than one spindle occurs in meiosis. In some PMCs, not all the chromosomes congregated at a single metaphase plate in metaphase I. Some of them (univalent) were scattered in the cytoplasm or remained in several small groups (Figure 2Q and R). In this case, not only bipolar spindles formed, but several mini-spindles were also induced by chromosomes that scattered in the cytoplasm. Multiple spindles are usually associated with abnormal cytokinesis, which will lead to polyad formation (Tilquin et al., 1984). It is obvious that most of the microspores and the pollen grains formed from them do not contain a normal haploid set of chromosomes, and they are non-functional. Abnormal chromosome segregation, microspores with micronuclei, and polyad formation are the manifestations of this irregularity (CaetanoPereira and Pagliarini, 2001). In the present study, irregular chromosome segregation (Figure $2 \mathrm{~K}$ ), microspores with micronuclei, and polyads were all observed (Figure 2L to O). All of these suggest that multiple spindles must have occurred in meiosis of the lily hybrids.

In some PMCs of 'Nymph', a certain percentage of chromosome stickiness was detected (Figure 2E and F). Chromosome stickiness is characterized by an intense clustering of chromosomes (Rao et al., 1990). Sticky chromosomes may result from the defective functioning of one or two types of specific non-histone proteins involved in chromosome organization, which are needed for chromatid separation and segregation. The altered functioning of these proteins will lead to stickiness of the chromosomes, which can cause chromosome aberrations 
by the physical stretching and breaking of chromatids at the sticky sites (Gaulden, 1987). The phenotypic manifestation of stickiness may be highly variable, ranging from a mild phenomenon (Figure 2E), when only a few chromosomes of the genome are involved, to an intense phenomenon (Figure 2F) involving the entire genome complements (Consolaro and Pagliarini, 1996; Pagliarini et al., 2000). At the end, the pollen will be sterile because of the chromosome pyknosis (Pagliarini et al., 2000).

\section{ACKNOWLEDGMENTS}

Research supported by the Public Sector (Agriculture) Scientific Research Funds (Project \#200903020), the Funding of the North American Lily Society (NALS), the China Scholarship Council (CSC), and the Dutch lily breeding companies.

\section{REFERENCES}

Ahmad QN, Britten EJ and Byth DE (1977). Inversion bridges and meiotic behavior in species hybrids of soybeans. $J$. Hered. 68: 360-364.

Asano Y (1978). Studies on crosses between distantly related species of lilies. III. New hybrids obtained through embryo culture. J. Jpn. Soc. Hortic. Sci. 47: 401-414.

Asano Y (1980). Studies on crosses between distantly related species of lilies. IV. The culture of immature hybrid embryos 0.3-0.4 mm long. J. Jpn. Soc. Hortic. Sci. 49: 114-118.

Asano Y and Myodo H (1977a). Studies on crosses between distantly related species of lilies. I. For the intrastylar pollination technique. J. Jpn. Soc. Hortic. Sci. 46: 59-65.

Asano Y and Myodo H (1977b). Studies on crosses between distantly related species of lilies. II. The culture of immature hybrid embryos. J. Jpn. Soc. Hortic. Sci. 46: 267-273.

Barba-Gonzalez R (2005). The Use of 2n Gametes for Introgression Breeding in Oriental x Asiatic Lilies. Master's thesis, Wageningen University and Research Centre, Wageningen.

Baskin TI and Cande WZ (1990). The structure and function of the mitotic spindle in flowering plants. Annu. Rev. Plant Biol. 41: 277-315.

Brandham PE (1969). Inversion heterozygosity and sub-chromatid exchange in Agave stricta. Chromosoma 26: 270-286.

Brandham PE (1977). The meiotic behaviour of inversions in polyploid Aloineae. Chromosoma 62: 69-84.

Caetano-Pereira CM and Pagliarini MS (2001). A new meiotic abnormality in Zea mays: multiple spindles associated with abnormal cytokinesis in both divisions. Genome 44: 865-871.

Comber HF (1949). A new classification of the genus Lilium. Lily Yearbook. J. Roy. Hort. Soc. 13: 86-105.

Consolaro MEL and Pagliarini MS (1996). Microsporocytes of Centella asiatica (L.) Urban (Umbelliferae). Cytologia 61: 57-61.

Couzin DA and Fox DP (1973). U-type exchange in tulip meiosis. Chromosoma 41: 421-436.

De Jong PC (1974). Some notes on the evolution of lilies. Lily yearbook, North Am. Lily Soc. 27: 23-28.

Frankel OH (1937). Inversions in Fritillaria. J. Genet. 34: 447-462.

Gaulden ME (1987). Hypothesis: some mutagens directly alter specific chromosomal proteins (DNA topoisomerase II and peripheral proteins) to produce chromosome stickiness, which causes chromosome aberrations. Mutagenesis 2: 357-365.

Jones GH and Brumpton RJ (1971). Sister and non-sister chromatid U-type exchange in rye meiosis. Chromosoma 33: 115-128.

Karlov GI, Khrustaleva LI, Lim KB and Van Tuyl JM (1999). Homoeologous recombination in $2 n$-gamete producing interspecific hybrids of Lilium (Liliaceae) studied by genomic in situ hybridization (GISH). Genome 42: 681-686.

Kitamura S, Akutsu M and Okazaki K (2009). Mechanism of action of nitrous oxide gas applied as a polyploidizing agent during meiosis in lilies. Sex Plant Reprod. 22: 9-14.

Kreft I (1968). Cytological studies on an inversion in barley. Hereditas 62: 14-24.

Lim KB (2000). Introgression Breeding Through Interspecific Polyploidisation in Lily: A Molecular Cytogenetic Study. Master's thesis, Wageningen University and Research Centre, Wageningen.

McRae EA (1998). Lilies: A Guide for Growers and Collectors. Timber Press, Portland. 
Morgan DT (1950). A cytogenetic study of inversions in Zea Mays. Genetics 35: 153-174.

Newman LJ (1966). Bridge and fragment aberrations in Podophyllum peltatum. Genetics 53: 55-63.

Pagliarini MS, De Freitas PM and Batista LAR (2000). Chromosome stickiness in meiosis of a Brazilian Paspalum accession. Cytologia 65: 289-294.

Rao PN, Ranganadham P and Nirmala A (1990). Behavior of a sticky desynaptic mutant in pearl millet. Genetica 81: 221-227.

Rieseberg LH, Baird SJ and Gardner KA (2000). Hybridization, introgression, and linkage evolution. Plant Mol. Biol. 42: 205-224.

Suzuki T and Tanaka I (1999). Attachment of kinetochores to spindle microtubules during meiosis I of Lilium microsporocytes. Chromosome Res. 7: 121-129.

Tilquin JP, Brouwer K and Horvat F (1984). Unusual cytological patterns in microsporogenesis in a cultivar of Fuchsia. Theor. Appl. Genet. 67: 413-417.

Ting YC (1965). Spontaneous chromosome inversions of Guatemalan teosintes (Zea mexicana). Genetica 36: 229-242.

Upcott M (1936). The parents and progeny of Aesculus carnea. J. Genet. 33: 135-149.

Upcott M (1937). The genetic structure of Tulipa II. Structural hybridity. J. Genet. 34: 339-399.

Van Tuyl JM, Van Diën MP, Van Creij MGM and Van Kleinwee TCM (1991). Application of in vitro pollination, ovary culture, ovule culture and embryo rescue for overcoming incongruity barriers in interspecific Lilium crosses. Plant Sci. 74: 115-126.

Van Tuyl JM, Lim KB and Ramanna MS (2002). Interspecific Hybridisation and Introgression. In: Breeding for Ornamentals: Classical and Molecular Approaches (Vainstein A, ed.). Kluwer Academic Publishers, Dordrecht, 85-103.

Yu HG, Muszynski MG and Kelly DR (1999). The maize homologue of the cell cycle checkpoint protein MAD2 reveals kinetochore substructure and contrasting mitotic and meiotic localization patterns. J. Cell Biol. 145: 425-435. 